\title{
Grafting of Polyesters on Carbon Black V. Preparation of Polyester-Grafted Carbon Black with a Higher Grafting Ratio by the Copolymerization of Epoxide with Cyclic Acid Anhydrides Using COOK Groups on Carbon Black as the Initiator
}

\author{
Norio TsuboKawa, Akihiro Yamada, and Yasuo Sone \\ Department of Applied Chemistry, Faculty of Engineering, \\ Niigata University, Ikarashi 2-8050, Niigata 950-21, Japan
}

(Received December 27, 1983)

\begin{abstract}
The ring-opening copolymerization of epoxides with cyclic acid anhydrides was found to be initiated by carbon black containing potassium carboxylate (COOK) groups to give alternating polymers, i.e., polyesters. Polyesters were propagated from COOK groups and effectively grafted on carbon black; for example, the grafting ratios of polyesters from glycidyl methacrylate and succinic anhydride and from styrene oxide and maleic anhydride were 126.2 and $51.5 \%$, respectively. The rate of copolymerization increased with increasing temperature, whereas the grafting ratio of polyesters decreased. The initiating activity of alkali metal carboxylate groups increased, depending on the type of alkali metal countercations, in the following order: $\mathrm{COOLi}<$ $\mathrm{COONa}<\mathrm{COOK}<\mathrm{COORb}<\mathrm{COOCs}$. This order was in agreement with that of increasing electropositivity of the countercations. In addition, the increasing electropositivity of the countercation caused an increase in the rate of chain transfer reaction, leading to a decrease in the grafting ratio and molecular weight of ungrafted polyesters. The effects of solvent on the copolymerization and grafting ratio are discussed.
\end{abstract}

KEY WORDS Ring-Opening Copolymerization / Polyester / Graft Polymerization / Carbon Black / Epoxide / Cyclic Acid Anhydride / Potassium Carboxylate Groups / Countercation / Grafting onto Carbon Black /

In a previous paper, we reported that the anionic ring-opening polymerization of $\beta$-propiolactone (PL) was initiated by alkali metal carboxylate (COOM: $\mathrm{M}=\mathrm{Li}, \mathrm{Na}, \mathrm{K}, \mathrm{Rb}, \mathrm{Cs}$ ) groups on the surface of carbon black and the polyester was effectively grafted onto carbon black. ${ }^{1}$ The rate of polymerization and grafting ratio of the polyester onto the surface of carbon black were remarkably affected by the ionic nature of alkali metal countercations, solvent, and polymerization temperature. ${ }^{1,2}$

Potassium carboxylate (COOK) groups on carbon black could also initiate the ringopening copolymerization of epoxides with phthalic anhydride to give polyester-grafted carbon black. ${ }^{3}$<smiles>[R]C(=O)OCc1coc(=O)o1</smiles><smiles>[R]C(COC([B])=O)OC(=O)[R]C(=O)O</smiles>

It was confirmed that the grafted polyester was propagated from COOK groups on the surface of carbon black and that the ungrafted polyester was gradually formed by chain trans- 
fer reaction of growing polymer anions. Therefore, it is expected that the propagation and chain transfer reaction of growing anions are controlled by polymerization conditions.

In the present paper, in order to obtain polyester-grafted carbon black with higher grafting ratio, the effects of polymerization temperature, alkali metal counter cation, and solvent on the grafting ratio of polyester were investigated. The alternating terpolymerization of epichlorohydrin, phthalic anhydride, and tetrahydrofuran using $\mathrm{COOK}$ groups as the initiator was also examined.

\section{EXPERIMENTAL}

\section{Materials}

The carbon black used was color channel black Neospectra II (Columbian Carbon Co., U.S.A., specific surface area; $906 \mathrm{~m}^{2} \mathrm{~g}^{-1}$ ) and the content of phenolic hydroxyl, quinonic oxygen, and carboxyl group was determined to be $0.24,0.92$, and 0.40 mequiv. $\mathrm{g}^{-1}$, respectively. ${ }^{4}$

Purification of glycidyl methacrylate (GMA), epichlorohydrine (ECH), and phthalic anhydride (PAn) was performed as previously described. ${ }^{3}$ Maleic anhydride (MAn) and succinic anhydride (SAn) were recrystallized from absolute chloroform and then sublimed under reduced pressure. Itaconic anhydride (IAn) was recrystallized from chloroform/ether and then sublimed under reduced pressure. Methylhexahydrophthalic anhydride (MHHPA), methyltetrahydrophthalic anhydride (MTHPA), and sty- rene oxide (SO) were distilled twice under reduced pressure. Tetrahydrofuran (THF) was refluxed over sodium hydride and distilled twice.

$N, N$-Dimethylformamide (DMF) was dried over calcium hydride and distilled under reduced pressure. Nitrobenzene was washed with dilute $\mathrm{H}_{2} \mathrm{SO}_{4}$, dried over $\mathrm{CaCl}_{2}$, and distilled in vacuo under nitrogen. $m$-Xylene was washed with concentrated $\mathrm{H}_{2} \mathrm{SO}_{4}$, refluxed over sodium, and distilled.

\section{Preparation of Carbon Black Containing COOM Groups}

Carbon black containing COOM groups was prepared by the reaction of carboxyl groups with alkali metal hydroxides. The procedure is described in the preceding paper. ${ }^{1}$

\section{Polymerization Procedures}

Under dry nitrogen, a freshly distilled epoxide $(0.01 \mathrm{~mol})$ was added to a $100 \mathrm{ml}$ teardrop flask containing $0.30 \mathrm{~g}$ of carbon black and $0.01 \mathrm{~mol}$ of a cyclic acid anhydride. When GMA, MAn, and IAn were used as monomers, $0.02 \mathrm{~g}$ of $N$-phenyl- $\beta$-naphthylamine was added to the reaction mixture to inhibit the radical cross-linking of the unsaturated polyester formed. The reaction mixture was stirred at $120^{\circ} \mathrm{C}$ at a constant rate with a magnetic stirrer.

After a definite time, the content of the flask was poured into a large excess of methanol to precipitate the polyester containing carbon black. The precipitate was dried at $40^{\circ} \mathrm{C}$ under vacuum and the conversion was calculated by the following equation.

$$
\text { Conversion }(\%)=\frac{\text { weight of precipitate }(\mathrm{g})-\text { added weight of carbon black }(\mathrm{g})}{\text { weight of monomer used }(\mathrm{g})} \times 100
$$

\section{Other}

The grafting ratio was determined by the following equation.
Grafting ratio $(\%)$

$$
=\frac{\text { weight of polyester grafted }(\mathrm{g})}{\text { weight of carbon black used }(\mathrm{g})} \times 100
$$

The intrinsic viscosity of ungrafted polyester was determined in chloroform solution at 
$30.0^{\circ} \mathrm{C}$.

\section{RESULTS AND DISCUSSION}

Copolymerization of Epoxides and Cyclic Acid Anhydrides Using COOK Groups on Carbon Black as the Catalyst

It is known that anionic catalysts, such as tertiary amines, ${ }^{5}$ alkali metal carboxylates, ${ }^{6}$ and organometallic compounds ${ }^{7}$ initiate the ring-opening copolymerization of epoxides with cyclic acid anhydrides to give alternating polymers, i.e., polyesters. In the previous paper, carbon black containing COOK groups was found to initiate the copolymerization of epoxide with PAn. ${ }^{3}$

Figure 1 shows both the time-conversion curve of the copolymerization of SO with MAn initiated by Neospectra II containing COOK groups and the relationship between the grafting ratio of the polyester and conversion. Copolymerization was also carried out with GMA, ECH, or SO as an epoxide and PAn, MAn, SAn, IAn, MHHPA, or MTHPA as an anhydride. The results are sum- marized in Table I.

As mentioned in the previous paper, ${ }^{3}$ neither an epoxide nor an anhydride alone was polymerized by carbon black containing COOK groups. However, Figure 1 and Table I

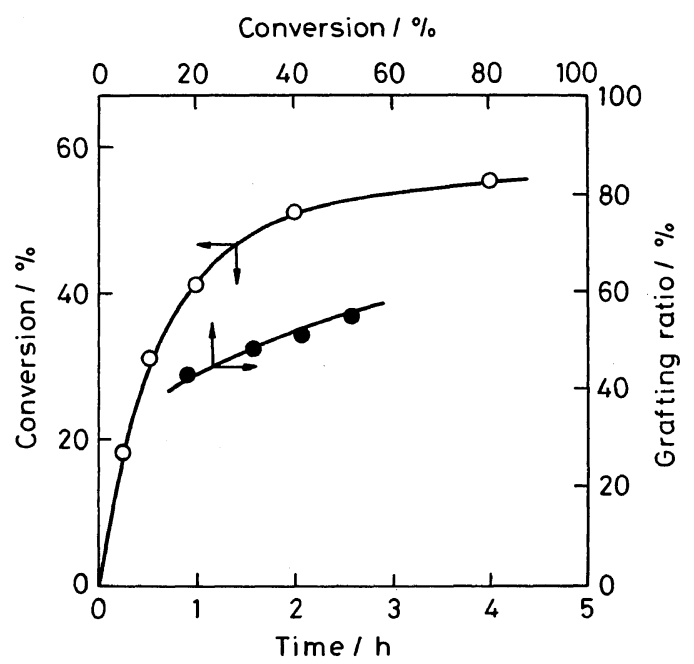

Figure 1. Copolymerization of SO with MAn initiated by COOK groups on the carbon black surface. COOKNeospectra II, $0.30 \mathrm{~g}$; SO $=$ MAn $=0.01 \mathrm{~mol} ; N$-phenyl$\beta$-naphthylamine, $0.02 \mathrm{~g} ; 120^{\circ} \mathrm{C}$.

Table I. Grafting of polyesters from epoxides and cyclic acid anhydrides on carbon black

\begin{tabular}{|c|c|c|c|c|c|}
\hline \multirow{2}{*}{ Epoxide } & \multirow{2}{*}{ Anhydride } & \multirow{2}{*}{$\frac{\text { Temp }}{{ }^{\circ} \mathrm{C}}$} & \multirow{2}{*}{$\frac{\text { Time }}{\mathrm{h}}$} & \multirow{2}{*}{$\frac{\text { Conversion }^{\mathrm{a}}}{\%}$} & \multirow{2}{*}{$\frac{\text { Grafting ratio }}{\%}$} \\
\hline & & & & & \\
\hline GMA & PAn & 120 & 1 & $46.5^{\mathrm{b}, \mathrm{d}}$ & 52.0 \\
\hline GMA & MAn & 120 & 1 & $80.0^{\mathrm{b}, \mathrm{d}}$ & 105.0 \\
\hline GMA & SAn & 120 & 1 & $46.3^{\mathrm{d}}$ & 126.2 \\
\hline $\mathrm{ECH}$ & PAn & 120 & 1 & 44.2 & 23.2 \\
\hline $\mathrm{ECH}$ & MAn & 120 & 1 & $44.7^{\mathrm{d}}$ & 44.2 \\
\hline $\mathrm{ECH}$ & SAn & 120 & 1 & 10.0 & 40.1 \\
\hline $\mathrm{ECH}$ & IAn & 120 & 1 & $30.7^{\mathrm{d}, \mathrm{e}}$ & - \\
\hline SO & PAn & 120 & 1 & 25.2 & 43.3 \\
\hline SO & MAn & 120 & 1 & $40.1^{\mathrm{d}}$ & 51.5 \\
\hline SO & SAn & 120 & 1 & 11.3 & 54.6 \\
\hline SO & MHНPA & 150 & 3 & $8.2^{\mathrm{c}}$ & 35.3 \\
\hline SO & MTHPA & 150 & 3 & $4.4^{\mathrm{c}}$ & 39.9 \\
\hline
\end{tabular}

a COOK-Neospectra II, $0.30 \mathrm{~g}$; epoxide $=$ anhydride $=0.01 \mathrm{~mol}$.

b Solution polymerization (nitrobenzene, $1.0 \mathrm{ml}$ ).

c Solution polymerization (nitrobenzene, $3.0 \mathrm{ml}$ ).

d $N$-Phenyl- $\beta$-naphthylamine $(0.02 \mathrm{~g})$ was added as an inhibitor of radical polymerization.

e Gel containing carbon black was obtained. 
show that when equimolar amounts of epoxide and anhydride were heated at $120-150^{\circ} \mathrm{C}$, copolymerization was initiated by $\mathrm{COOK}$ groups on the carbon black to give a polymer. The carbon black obtained from the polymerization gave a stable colloidal dispersion in a good solvent for polyesters such as chloroform. This suggests grafting of the polyester on the surface of carbon black. The grafting ratio was determined and the results are shown in Figure 1 and Table I.

Figure 1 shows that the grafting ratio increases with an increase in conversion. Thus, the polyester is propagated from COOK groups on the carbon black. Moreover, in Table I, it is evident that various kinds of polyester can be grafted from carbon black.

The ungrafted polyesters obtained from the copolymerization of epoxides with anhydrides were identified as the expected polyesters by the IR and ${ }^{1} \mathrm{H}$ NMR spectra. For example, with ECH and PAn as monomers, a perfect alternating polymer should have the following repeating unit:<smiles>[CH2]CC(CCl)OC(=O)C1C=CC(=O)C1[O+]</smiles>

IR (KBr); 1720 (vs; C=O), 1660 and 1580 (m; $o$-phenylene), $1120(\mathrm{~s} ; \mathrm{C}-\mathrm{O}-\mathrm{C})$, and $1070 \mathrm{~cm}^{-1}$ (s; C-O-C). ${ }^{1} \mathrm{H}$ NMR $\left(\mathrm{CDCl}_{3}\right) ; \delta=3.63-3.97$ $\left(2 \mathrm{H},-\mathrm{CH}_{2} \mathrm{Cl}\right), \quad 4.43-4.77\left(2 \mathrm{H},-\mathrm{CH}_{2}-\mathrm{O}-\right)$, $5.33-5.70(1 \mathrm{H},=\mathrm{CH}-)$, and $7.33-7.86 \mathrm{ppm}$ (4H,o-phenylene). The polyester from GMA and MAn should have the following repeating unit:<smiles>C=C(C)C(=O)OCC(CC)OC(=O)C=CC(=O)O</smiles>

IR (KBr); 1730 (vs; C=O), 1660 (m; $-\mathrm{C}=$ $\left.\mathrm{CH}_{2}\right), 1150$ (s; C-O-C), and $1090 \mathrm{~cm}^{-1}(\mathrm{~m}$; $\mathrm{C}-\mathrm{O}-\mathrm{C}) .{ }^{1} \mathrm{H}$ NMR $\left(\mathrm{CDCl}_{3}\right) ; \delta=1.73-2.03$ $\left(3 \mathrm{H},-\mathrm{CH}_{3}\right), \quad 3.93-4.70 \quad\left(4 \mathrm{H},-\mathrm{CH}_{2}-\mathrm{O}-\right)$, $5.40-5.70\left(2 \mathrm{H}, \quad=\mathrm{CH}_{2}\right), 5.93-6.15(1 \mathrm{H}$, $=\mathrm{CH}-)$, and $6.18-6.40 \mathrm{ppm} \quad(2 \mathrm{H}$, $-\mathrm{CH}=\mathrm{CH}-$ ).

It is concluded that COOK groups on carbon black can initiate the alternating copolymerization of epoxides with cyclic acid anhydrides, and various kinds of polyesters can be propagated from the carbon black surface.

\section{Effects of Temperature on the Copolymeriza- tion of ECH with PAn}

The copolymerization of $\mathrm{ECH}$ with PAn was carried out at 100,120 , and $140^{\circ} \mathrm{C}$ using Neospectra II containing COOK groups and the results are shown in Figure 2.

The rate of the copolymerization increased with an increase in temperature. The Arrhenius plots for the above results gave a straight line and the apparent activation energy of the copolymerization was estimated to be $12.6 \mathrm{kcal} \mathrm{mol}^{-1}$. The activation energy for the copolymerization of GMA with MAn was determined to be $22.0 \mathrm{kcal} \mathrm{mol}^{-1}$.

The activation energy for the copolymerization of phenoxypropenoxide with PAn using disodium phthalate was reported to be 16

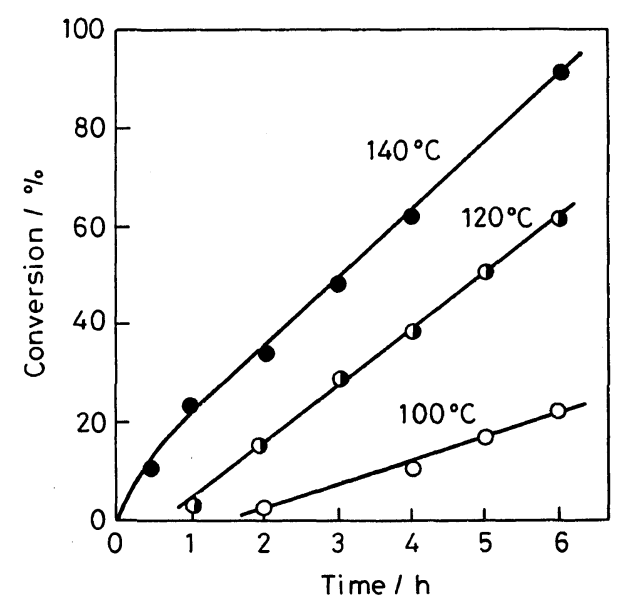

Figure 2. Effect of temperature on the copolymerization of ECH with PAn. COOK-Neospectra II, $0.30 \mathrm{~g}$; $\mathrm{ECH}=\mathrm{PAn}=0.01 \mathrm{~mol}$; nitrobenzene, $3.0 \mathrm{ml}$. 
$\mathrm{kcal} \mathrm{mol}^{-1}$ by Schwenk et al. ${ }^{6}$ Therefore, the activation energy for the copolymerization initiated by COOK groups appears to be close to that initiated by disodium phthalate.

\section{Effects of Temperature on the Grafting Ratio of} Polyesters

As mentioned above, in such copolymerization systems, polyesters were propagated from the carbon black surface and ungrafted polyesters were gradually formed by a chain transfer reaction of growing anions. To obtain a polyester-grafted carbon black with a higher grafting ratio, it is necessary to control the chain transfer reaction. The effects of temperature on the grafting ratio of polyesters were thus investigated. As shown in Figure 3, at each temperature, the grafting ratio increased with an increase in conversion. In addition, it is apparent that the grafting ratio on carbon black decreased, depending on the polymerization temperature, in the following order: $100>120>140^{\circ} \mathrm{C}$. That is, the result indicates that increasing temperature increases the formation of ungrafted polyesters.

These results can be explained as follows. The grafted polyester is propagated from COOK groups on the surface of carbon

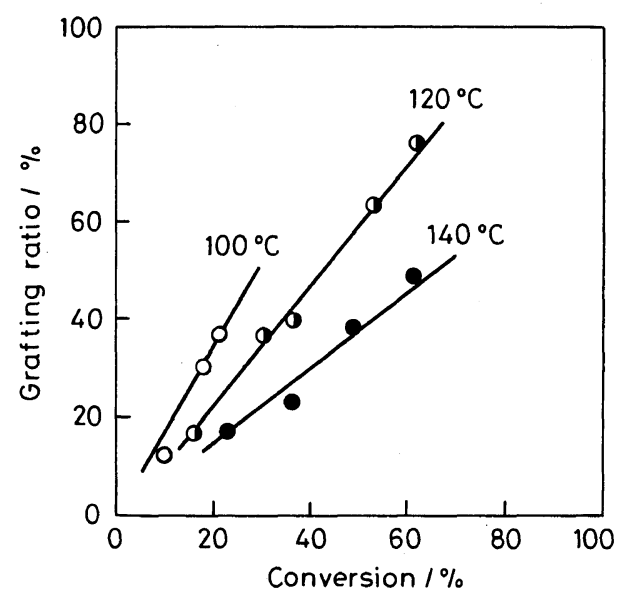

Figure 3. Effect of temperature on the grafting ratio of polyester from ECH and PAn. Polymerization conditions are given in Figure 2. black. ${ }^{3}$ Thus, increasing polymerization temperature causes an increase in the rate of chain transfer reaction. Accordingly, when the copolymerization is carried out at lower temperatures, the polyester-grafted carbon black with a higher grafting ratio is obtained.

\section{Effects of Alkali Metal Countercations on the Copolymerization}

To elucidate the effect of alkali metal countercations $\left(\mathrm{M}^{+}\right)$on the copolymerization, the copolymerization of GMA with PAn initiated by COOLi, COONa, COORb, and COOCs groups on carbon black was compared with that of COOK groups.

As shown in Table II, the rate of the copolymerization initiated by COOM groups on the surface increased in the following order: $\mathrm{COOLi}<\mathrm{COONa}<\mathrm{COOK}<\mathrm{COORb}<$ COOCs. This order is in agreement with that of the increasing electropositivity of these alkali metals.

Similar effects of countercations were observed in the ring-opening polymerization of PL initiated by COOM groups. ${ }^{1}$ Sittler and Sebenda reported that the dissociation constant of alkali salts of $\varepsilon$-caprolactam increased in the order of increasing electropositivity of alkali metal cations and agrees with the increasing polymerization activity of the salts. ${ }^{8}$ The effects of alkali metal countercations on

Table II. Effects of alkali metal countercations on the copolymerization of GMA with PAn

\begin{tabular}{lcc}
\hline & COOM & Conversion \\
\cline { 3 - 3 } Treated carbon black & group & $\%$ \\
\hline Untreated Neospectra II & - & 0 \\
LiOH-Neospectra II & COOLi & 22.2 \\
NaOH-Neospectra II & COONa & 26.2 \\
KOH-Neospectra II & COOK & 32.0 \\
RbOH-Neospectra II & COORb & 44.1 \\
CsOH-Neospectra II & COOCs & 55.2 \\
\hline
\end{tabular}

a COOM-Neospectra II, $0.30 \mathrm{~g} ; \mathrm{GMA}=\mathrm{PAn}=0.01 \mathrm{~mol}$; $N$-phenyl- $\beta$-naphthylamine, $0.02 \mathrm{~g}$; temp, $120^{\circ} \mathrm{C}$; time, $2 \mathrm{~h}$. 


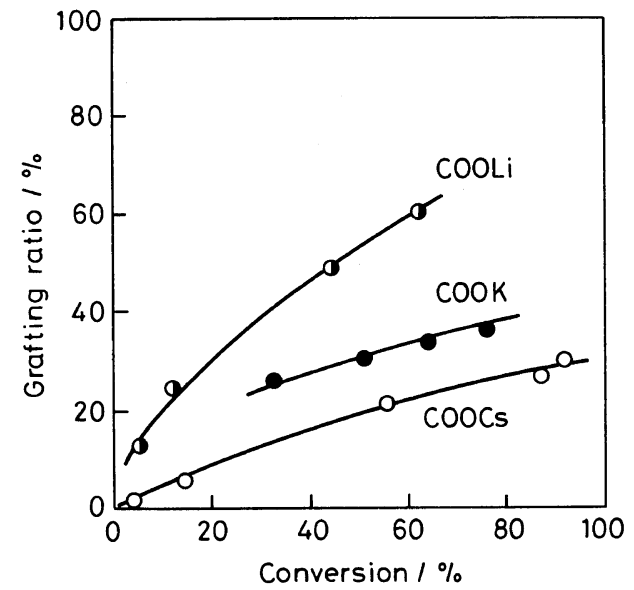

Figure 4. Effect of alkali metal countercations on the grafting ratio of polyesters from GMA and PAn. COOM-Neospectra II, $0.30 \mathrm{~g} ; \mathrm{GMA}=\mathrm{PAn}=0.01 \mathrm{~mol}$; $N$-phenyl- $\beta$-naphthylamine, $0.02 \mathrm{~g}$; nitrobenzene, $3.0 \mathrm{ml}$; $120^{\circ} \mathrm{C}$.

the copolymerization of GMA with PAn can thus be explained as follows. The growing chains are considered to be ion pairs such as $\mathrm{CB}^{\sim} \mathrm{COO}^{-} \mathrm{M}^{+}$or $\mathrm{CB} m \mathrm{O}^{-} \mathrm{M}^{+}{ }^{6}$ The increasing electropositivity of alkali metals causes an increase in the dissociation constant of growing chains, leading to a greater polymerization rate.

\section{Effects of Alkali Metal Countercations on}

Grafting Ratio and Molecular Weight of

Ungrafted Polyesters

The effects of alkali metal countercations on the grafting ratio were studied. The results are shown in Figure 4.

The grafting ratio of the polyester on carbon black surface was found to decrease, de-

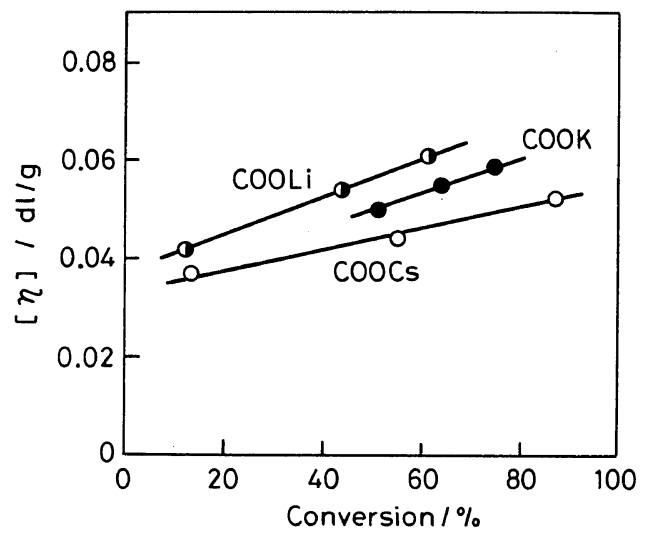

Figure 5. Effect of alkali metal countercations on the intrinsic viscosity of ungrafted polyesters. Polymerization conditions are given in Figure 4. [ $\eta]$, chloroform; $30.0^{\circ} \mathrm{C}$.

pending on the countercations, in the following order: $\mathrm{COOLi}>\mathrm{COOK}>\mathrm{COOCs}$. This order is in agreement with that of the decreasing electropositivity of these alkali metals. Figure 5 shows the effects of alkali metal countercations on the intrinsic viscosity of the ungrafted polyesters. The molecular weight of the ungrafted polyesters decreased with an increase in the electropositivity of these alkali metals.

It may be concluded that an increase in the electropositivity of the countercations causes an increase in the ionic nature of the ion pair of growing chains. This leads to a greater attraction of active hydrogens from impurities, such as water and dicarboxylic acid, by the growing polymer anions. ${ }^{6}$ Accordingly, when COOCs groups are used, a lower grafting ratio and an ungrafted polyester with a lower molecular weight result.

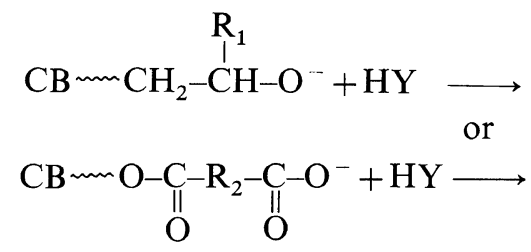

Effects of Solvent on the Copolymerization of ECH with PAn

The effects of solvent on the copolymeri-<smiles>[Y]CC([R])O</smiles><smiles>[10BH3]</smiles><smiles></smiles> 


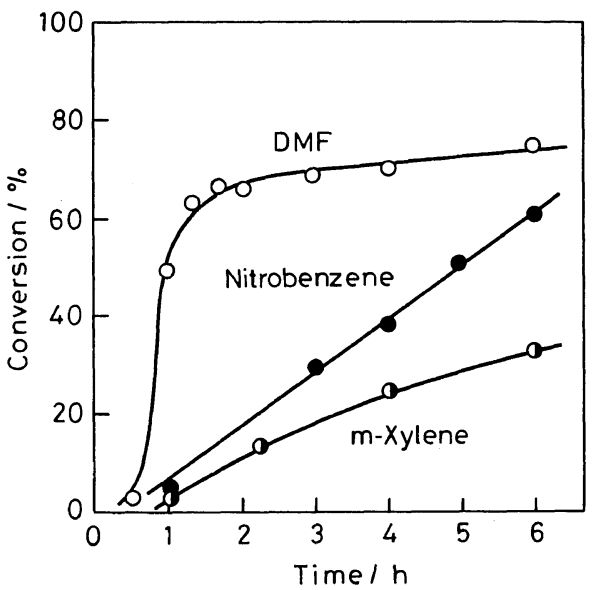

Figure 6. Effect of solvent on the copolymerization of $\mathrm{ECH}$ with PAn. COOK-Neospectra II, $0.30 \mathrm{~g} ; \mathrm{ECH}=$ $P A n=0.01 \mathrm{~mol}$; solvent, $3.0 \mathrm{ml} ; 120^{\circ} \mathrm{C}$.

Figure 6 indicates that the rate of the copolymerization increased, depending on the solvent used, in the following order: $m$-xylene < nitrobenzene $\ll \mathrm{DMF}$. This order is in agreement with that of the increasing dielectric constants of these solvents. That is, copolymerization was found to accelerate in a polar solvent, particularly in DMF. Similar solvent effects were observed in the anionic ringopening copolymerization of phenoxypropenoxide with PAn initiated by disodium phthalate. ${ }^{6}$ We also reported that the anionic ring-opening polymerization of PL initiated by COOK groups on carbon black was accelerated in a polar solvent. ${ }^{2}$ These phenomena are explained as follows. The increasing dielectric constant of solvent causes an increase in the separation of the ion pairs $\left(\mathrm{CB} \sim \mathrm{COO}^{-} \mathrm{K}^{+}\right.$ or $\mathrm{CB} \sim \mathrm{O}^{-} \mathrm{K}^{+}$) by the solvation of the countercation $\left(\mathrm{K}^{+}\right) .^{2,9-11}$ Thus, an increase in charge separation of the ion pairs increases the effective charge of carboxylate or alcoholate anions to cause an increase in the rate of copolymerization.

Effects of Solvent on Grafting Ratio and Molecular Weight of Ungrafted Polyesters

The rate of copolymerization was remark-

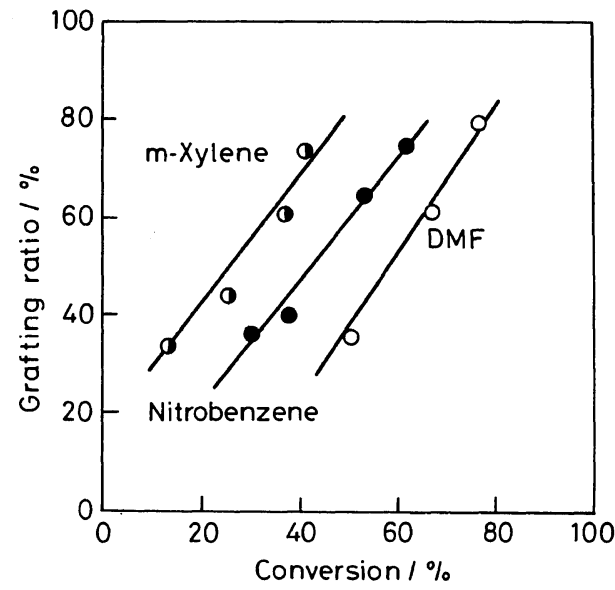

Figure 7. Effect of solvent on the grafting ratio of polyesters from ECH and PAn. Polymerization conditions are given in Figure 6.

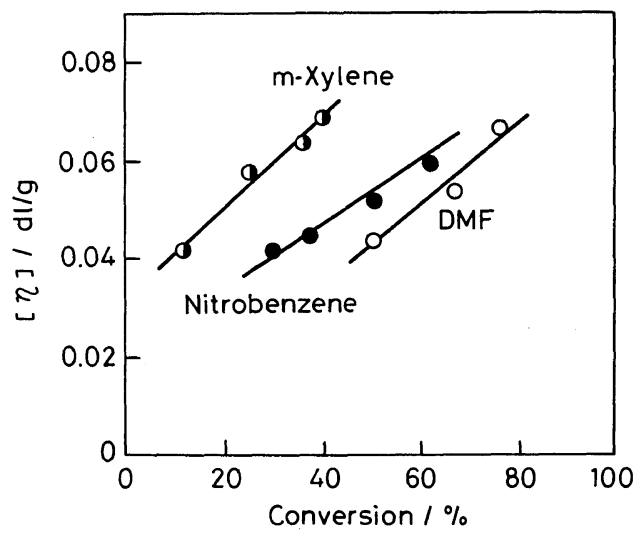

Figure 8. Effect of solvent on the intrinsic viscosity of ungrafted polyesters. Polymerization conditions are given in Figure 6. $[\eta]$, chloroform; $30.0^{\circ} \mathrm{C}$.

ably affected by the dielectric constant of the solvent. Clarification should be made of the effects of solvent on the grafting ratio and the molecular weight of ungrafted polyesters.

Figure 7 shows the effects of solvent on the grafting ratio of the polyester from $\mathrm{ECH}$ and PAn. The grafting ratio of the polyester on carbon black clearly varied according to the solvent used in the following order: DMF < nitrobenzene $<m$-xylene. This order is in agreement with that of the decreasing dielectric constants of the solvents.

Figure 8 shows the effects of solvent on the 
intrinsic viscosity of the ungrafted polyester. The intrinsic viscosity of the ungrafted polyester decreased as the dielectric constant of the solvent increased, i.e., $m$-xylene with the lowest dielectric constant gave the highest grafting ratio and the polyester of the highest molecular weight.

The explanation for this is as follows. The polyester is propagated from COOK groups on the carbon black surface and the increasing dielectric constant of the solvent increases the negative charge of the propagating anion by solvation. Thus, the increasing negative charge of the propagating anion leads to greater attraction of active hydrogens from impurities such as water or dicarboxylic acid present in the copolymerization system (chain transfer reaction). ${ }^{12}$ Consequently, a lower grafting ratio and the ungrafted polyester with a lower molecular weight result, when a solvent with a higher dielectric constant such as DMF is used.

\section{Copolymerization of ECH with PAn in THF}

Hsieh reported that when the copolymerization of ECH with PAn was carried out in excess of THF using trialkylaluminum as the catalyst, an alternating $1: 1: 1$ terpolymer, $\cdots$ ABCABC $\cdots$, was obtained. ${ }^{13}$

The copolymerization of ECH with PAn in THF initiated by COOK groups on carbon black was thus investigated. In the presence of COOK-Neospectra II $(0.30 \mathrm{~g})$, equimolar amounts $(0.01 \mathrm{~mol})$ of $\mathrm{ECH}$ and PAn were heated in $5.0 \mathrm{ml}$ of THF at $70^{\circ} \mathrm{C}$ for $24 \mathrm{~h}$. The product was an alternating polyester from $\mathrm{ECH}$ and PAn, whereas no terpolymer from ECH, PAn, and THF was obtained at all.

The grafting of polyesters by a similar ringopening copolymerization of alkylene carbonates with cyclic acid anhydrides is now being investigated.

\section{CONCLUSIONS}

The carbon black containing COOK groups was capable of initiating the alternating ringopening copolymerization of epoxides with cyclic acid anhydrides to give polyesters. Accordingly, it became feasible to graft various kinds of polyesters on the carbon black surface. The rate of copolymerization and grafting ratios of polyesters were found to be affected by polymerization temperature, the ionic nature of countercations, and the dielectric constant of the solvent used. Thus, to obtain the polyester-grafted carbon black with a higher grafting ratio, copolymerization should be carried out at lower temperatures using alkali metal countercations with lower electropositivity and solvents with lower dielectric constants.

\section{REFERENCES}

1. N. Tsubokawa, A. Funaki, Y. Hada, and Y. Sone, $J$. Polym. Sci., Polym. Chem. Ed., 20, 3297 (1982).

2. N. Tsubokawa, A. Funaki, Y. Hada, and Y. Sone, Polym. Bull., 7, 589 (1982).

3. N. Tsubokawa, A. Yamada, and Y. Sone, Polym. Bull., 10, 63 (1983).

4. N. Tsubokawa, H. Matsumoto, and Y. Sone, J. Polym. Sci., Polym. Chem. Ed., 20, 1943 (1982).

5. R. F. Fisher, J. Polym. Sci., 44, 155 (1960).

6. E. Schwenk, K. Gulbins, M. Roth, G. Benzing, R. Maysenhölder, and K. Hamann, Makromol. Chem., 51, 53 (1962).

7. K. Matsuura, S. Inoue, Y. Terada, and T. Tsuruta, Kogyo Kagaku Zasshi, 69, 707 (1966).

8. E. Sittler and J. Sebenda, J. Polym. Sci., Part C, 16, 67 (1967).

9. K. F. O'Driscoll and A. V. Tobolsky, J. Polym. Sci., 35, 259 (1959).

10. F. J. Welch, J. Am. Chem. Soc., 82, 6000 (1960).

11. M. Szwarc, Adv. Polym. Sci., 2, 300 (1960).

12. A. Zilkha and Y. Katz, J. Polym. Sci., 62, 153 (1962).

13. H. L. Hsieh, J. Macromol. Sci.-Chem., A7, 1525 (1973). 